\title{
SOCIO-CULTURAL DYNAMICS OF SOCIAL PHENOMENA OF THE RUSSIAN CIVILIZATION
}

\author{
Valeriya Leonidovna Vorontsova ${ }^{1}$, Maksim Vladimirovich Salimgareev ${ }^{2}$, Dmitriy Vladimirovich \\ Salimgareev $^{3}$, Albert Vildanovich Ramazanov ${ }^{4}$ \\ ${ }^{1} \mathrm{PhD}$ in Mathematics and Mechanics, Associate Professor, Kazan Federal University, Russia, ${ }^{2} \mathrm{PhD}$ in History, \\ Associate Professor, Kazan State Technological University, Russia, ${ }^{3}$ Assistant of Professor, Kazan State University of \\ Culture and Arts, Russia, ${ }^{4} \mathrm{PhD}$ in Economics, Associate Professor, Kazan Federal University 18, Kremlevskaya str., \\ Kazan, Russia. \\ Email: milen99@yandex.ru
}

Article History: Received on $30^{\text {th }}$ June 2019, Revised on $30^{\text {th }}$ July 2019, Published on $18^{\text {th }}$ September 2019

\begin{abstract}
Purpose: Identification of the heuristic significance of radicalism and solidarity as elements of the Russian civilization concept, not only within the framework of a unified, strictly fixed theory, but as universal intellectual tools of a modern socio-humanitarian vision of historical reality.

Methodology: The basis of the work is a civilizational approach, which allowed to most effectively evaluate the interesting aspects of the social development of Russian civilization.

Main Findings: The authors revealed the specific content of national manifestations of radicalism and solidarity in a philosophical and historical context. The most important manifestations of the social aspirations of key mega-objects of Russian history: the ethnic group, the state and the church are analyzed. When considering the historical specifics of the designated vectors of civilizational dynamics, attention is drawn to the role of individuals in the process of activating or deactivating the indicated directions of Russia development.

Novelty/Originality: The authors revealed the specific content of national manifestations of radicalism and solidarity in a philosophical and historical context. The tendency towards radical and solidary forms of interaction among the participants in the civilization process, especially at the tragic moments of historical changes, was a special form of manifestation of social dynamics. Its total completeness, expressed, among other things, through the acceleration or deceleration of the adaptation to historical reality processes, became a state of self-disclosure of specific subjects of social action, acting as vehicles of unknown metahistorical forces.
\end{abstract}

Keywords: solidarity, Russian history, ethnicity, statehood, church, civilization.

\section{INTRODUCTION}

The ontological reality of Russian civilization, its vital manifestation in internal and external forms was carried out due to the deep impulses of its cultural core. In the content of the nucleus, in addition to possible other components, such as radicalism and solidarity were present. Understanding the logic of their functioning in the process of sociocultural dynamics, the algorithm of their movement at critical moments of civilizational development can provide a more holistic picture of historical reality, increases the chances of adequacy of the vision of the trajectory of future transformations.

\section{LITERATURE REVIEW}

The term radicalism (from the Latin. Radix) entered into the social science discourse at the end of the XVIII century. In the Dahl dictionary, the term means "fundamental" and the radical is "a politician requiring fundamental changes in management based on science rejecting experience" (Dal V., 1995). In scientific reference books, radicalism is understood as the theory and political practice of "decisive measures aimed at implementing fundamental social transformations" (Political Science Dictionary, 1994). In our opinion, radicalism in the context of civilizational development, one can understand any voluntarist action or plan aimed at such a change in the external or internal conditions of a particular sociocultural community that is carried out or planned using extreme, including violent forms of social action.

The term "solidarity", in the ancient Roman right "insolidum" (for the whole), meant a joint contractual obligation of all debtors to repay the debt as a whole. Perhaps Pierre Leroux was the first to use it, borrowing the term from medieval jurists for its use in philosophy (Blais M.-C., 2007). "Solidarity" in modern social philosophy is defined as the normative reflection of the ontological essence of people's life in society, their initial, internal unity. At the same time, it is a principle that determines the social connection between individuals, social actors, actions within small and large groups of people based on kinship, neighborhood, common work, interests, etc. (Eisenstadt S., 1978). By solidarity, it is necessary to understand the correlative, complementary state arising between individual individuals or social groups, based on the experience of the "other", forming an integral unity of people and their communities, who perceive their common destiny through appropriate cultural codes. 
The social existence of the Russian civilization for a long time is due to the complex combinations of radicalism and solidarity as elements of the cultural core, aimed at the survival of a socio-cultural organism. Obviously, these phenomena initially arise as biopsychological regulators inherent in all mankind; therefore, the history of any country has not been without radical shocks, without consolidating phenomena revealing the potential of the human spirit in its desire to overcome the original natural principle in being.

The behavioral reactions of cohesion or aggression appear to be associated not only with rational structures of consciousness, but with the unconscious sphere and emotions (Ridley, 2014). The natural desire to defend oneself from external or internal violence leads to striving in various ways, for example, at the expense of cohesion or retaliatory aggression, to safeguard social integrity, which is characteristic of both primates and people (Modern philosophy, 1995). It can be assumed that the phenomena of radicalism and solidarity as a reaction to the environment are due to the fear of destruction, which in itself is a powerful incentive for the emergence of society and its social institutions (vendetta, law, the state, etc.). Thus, cultural phenomena of radicalism and solidarity are initially rooted in the structure of both the individual psyche and the level of collective consciousness. They manifest themselves in stereotypical behavior as a complex of neurotic, unconscious intentions. This assumption is confirmed by the latest research in the field of neurophysiology, psychology and genetics. Representatives of these branches of knowledge about a person found that the propensity to one or another political views is largely due to biochemical reactions that depend on heredity no less than the level of assimilation of certain social norms and ideas (Martin N.G., Eaves L.J., Heath A. C.Et., 1986). However, such an approach with its scientific arguments is not able to bring us closer to understanding the multifaceted cultural and historical essence of radicalism and solidarity (Navarette, 2006).

Cultural stereotypes play an important role in the forms of manifestation of radicalism and solidarity. So, D. Likhachev noted such a property of Russian character as metaphysical tendency towards the limit. In the burst of disruptive in all things to reach the boundaries of the possible, he saw a hidden deep tragic feature of all national culture and history Another feature of the "mental map" that influenced the specifics of the Russian model of radicalism and solidarity is due to the formula where society is perceived as "an augmented or expanded personality, and a personality is a compressed, concentrated society". (Likhachev D.S., 1990). In this situation, the categories in question are perceived as principles that include not only individualism, but also collectivism.

\section{METHODS}

For a long time in Russian history, human existence has been defined through the striving for "personal-social", where the dichotomy of these principles should be removed by deep synthesis. As for the mechanisms for implementing these features, the important factors of the Russian civilization are the actions of key actors: the ethnic group, the state and the church. For a long time it was they who determined the severity of the cultural core and all its elements, among which we include radicalism and solidarity.

When analyzing the radicalism and solidarity manifested in Russian civilization, it is important to take into account the fact that these phenomena are mentally determined by permanently acting factors of social organization. One of the key components of social organization is ethnographic. Solving the outbreak of conflicts, trying to survive in adverse conditions, the population of the country for long historical periods was integrated into various social corporations. At the same time, they could use not only rational forms and methods of hostel, adaptations to each other, but also, as V.O. Klyuchevsky, "migratory wandering", divergence in different directions (Klyuchevsky V.O., 1990).

The peculiarity of this phenomenon in the history of the Russian civilization stages in question was determined by the situation of poly-ethnicity, which permanently created a special intensity of shared feelings. The palette of multinationality was formed as a result of long and numerous migrations on the vast spaces of Eurasia. The variety of the Russian ethnic and cultural peculiarities is striking. It was precisely diversity that became the foundation of "worldwide responsiveness", which consists in the deep empathy of another, "the ability to absorb the spirit and ideas of foreign peoples, to transform into the spiritual essence of all nations" (Klyuchevsky V.O., 1990).

Cultural complementarity, the ability to inter-ethnic solidarity to a certain extent due to the adoption of Christianity with its focus on transcendental humanity. The spread of monotheism and written culture intensified as the state expanded, which brought the people of the country to an unprecedented level of inter-ethnic consolidation. However, this process has always been opposed by the oral tradition, with its emphasis on loci directed inward to ethnicity, to ancestral roots, the "smell of earth", where solidarity cannot operate on large scales of space and time.

The functioning of this centripetal principle is associated with a high degree of micro-social consolidation, which can be seen in the example of the peasant land community that emerged in the era of the Moscow centralized state. Being an autonomous self-governing unit, it united its members not only with common economic concerns, but also spiritually (inside the church parish). Solidarity relations within the community persisted until the beginning of the 20th century (Soloviev V.S., 1988). In such a patriarchal economy, a leveling, economically inefficient land use was established, this state of affairs in the highest sense implemented the principles of solidarity and justice, reflecting the essence of the world view of farmers who saw the God truth in them (Rittikh A. A., 1903). 
At the same time, under the influence of external and internal factors, the political vector begins to dominate the creation of the nation. This tendency did not mean that ethnic localization was completely leveled out; it did not exist for a long time, and in certain regions even dominated (Malinkovich, 2008). Thus, the striving of ethnic groups towards closure in local contours of solidarity reveals itself, for example, in the Volga region. After the conquest of Kazan, the Tatars, who had lost their statehood, and with it some civilization signs (urban life, urban culture), were forced to activate their ethnic locus (Russia, 1993). The closure on the intra-communal, intra-Islamic, intra-ethnic contour hampered their development, until the second half of the 19th century, when, thanks to the Jadidism movement, an attempt was made to establish closer contact with the Russians. The ethno-cultural transformation that began at the end of the 19th century set a definite historical vector of movement towards interfaith, inter-ethnic solidarity based on mutual awareness of the common historical path.

Obviously, the key unifying factor in the history of Russia was the state. As G. Grossman notes, Russia has long been "ruled by autocratic kings with the help of a centralized state, bureaucracy, the official church, and a leading ideology. The tsarist concept of Russian society was at the same time the concept of solidarity" and the state sought to identify itself with society (Grossman G., 1970). Having experienced the deepest deformation in the era of Horde rule, the Russian model of statehood from the end of the 15th century found signs of great power. Continuing to integrate the peoples into a single ethno-cultural space, resorting to the help of religion, its solidarizing properties, which ideologically held together the emerging land communities, it spread the ideology of the Orthodox kingdom. It is symptomatic that A. Toynbee sees the conjugation of the development of civilizations with world religions, which basically form a special form of solidarity integrating heterogeneous ethnic and cultural foundations. Claiming universal connections between people of different ethnic groups and states, they simultaneously weaken the relationship of the individual with his original natural and social environment. While strengthening the supra-empirical solidarity of believers among themselves through the super-object. Thus, spiritual involvement at the interpersonal level was identified with "vertical ascent" through "cordiality" to "metaphysical depth" leading to Salvation (Toynbee A., 1991).

In Russia, the concept of "salvation" has long "retained its metaphysical interpretation, asserting the possibility of direct conjugacy of the far and upper worlds. The Orthodox, first of all, Russian spirituality, turned out to be firmly tied to the "beyond" aspirations of higher individual impulses with the almost complete neglect of a social affair " (Spiridonov V.I., 2008). Acknowledging the highest truth of "unity in spirit", the religious monotheistic, primarily Christian, consciousness moved along the path to universal solidarity, exceeding the measure of both communal and ethnic and state consolidation (Glinchikova, 2014).

In the axial time of the history of Russia, which coincided with the period of the historical strengthening of the state and the church (mid XVII - early XVIII century), a unique situation of a radical collision of different vectors of solidarity arises: statistically, religiously and spontaneously popular. The strengthening of great power under Alexey Mikhailovich coincided with the powerful theocratic claims of the church. Nikon's reforms were directed against the tradition of "ethnographic Orthodoxy", closed on intra-ethnic loci. They took the church to the intercontinental, interstate level. Perceived by wide circles as an open attempt on the national religious feeling and dignity of the people, the reforms catalyzed a civilizational crisis. (Soloviev V.S., 1990).

Focusing on civilizational, inter-ethnic solidarity, Peter I was the most significant and ambitious radical in the history of Russia. Peter's reconstruction of statehood took place according to Hegel. In order for loci seeking to narrow the solidarization space, not to take root and not to strengthen themselves in this isolation, "the government must from time to time internally shake them through wars, violate these and upset the established order and law independence" (Hegel G.W.F., 1959).

\section{RESULTS}

One of the components of the problem under consideration is the fact that Russian civilization has not bypassed the panEuropean phenomenon of revolutions. The idea of a revolutionary coup, as is well known, first expressed by Thomas Müntzer, was embodied in Russia in particular. And although A.S. Pushkin, who specially studied the phenomenon of the Pugachev rebellion, could not allow the boom of radicalism in his homeland, several decades passed, and a revolutionary tradition began to take shape in it ideologically.

At the time of its maturation (middle and second half of the XIX century) in the depths of the consciousness of domestic intellectuals, reflected in letters, manuscripts, appeals, literary articles or works, on the pages of various printed revolutionary texts, this tradition fed a special desire for solidarity. Apparently, the intelligentsia inherited a tendency to sympathy towards the crushed classes of the empire not only from A.N. Radishcheva, this ability was a certain psychological attitude of her Christianized consciousness.

\section{DISCUSSION}

In this connection, the religious thought of pre-revolutionary and revolutionary decades became an important direction of understanding the solidaristic intentions of society. This thought formed the understanding that a genuine, good change in the harsh living conditions of the peoples of Russia is possible only on the basis of moral recovery, the 
rehabilitation of kindheartedness towards one's political opponents, the acceptance of a different opinion and another life as an eternal value (Hegel G.W.F., 1959). Otherwise, any external and, in particular, violent change in the sociopolitical reality, the desire to translate his vision of justice by force, most likely, will turn into a senseless and merciless bloody whirlwind (Spiridonov V.I., 2008).

However, all these warnings were not taken, neither in the "lower classes" nor in the "top". Neither the Narodniks, nor the Anarchists, nor, the more so. Social Democrats, who had turned their heightened ability to empathize the oppressed strata into total hostility towards "class enemies", could hear it. The intellectual trends of Europe and the cataclysmsgrimaces of the historical path of the Western world instilled in the emerging revolutionary hypotheses of Russian intellectuals and their adherents who grew up on the basis of national civilization, the spirit of irreconcilable solidary radicalism manifested in Bolshevism. The latter, who inflamed the rebellious moods of the crowds, saw in the social crisis of the first decades of the 20th century both the breeding ground for his power encroachments, and the historical inevitability of his victory.

\section{SUMMARY}

As is known, the call to violence and its realization, the break with the past and the radical total breakdown of social foundations in the whirlwind of the changes that are taking place can be considered essential features of the social revolution. Summarizing the experience of the European social movements of the New Time, it can be noted that by working out the principles of political legitimacy, the Europeans moved from political upheavals to revolutions. In Russia, timekeeping was not different, the essence of the emerged situation of a social rift at the beginning of the 20th century was obvious.

The change of power from one to another and the idea of rebellion cleared the idea that "legal representatives of society" are capable of rebuilding the social and political order, on the basis of social harmony and universal happiness. However, a new aspect of the legitimacy of the emerging revolutionary power was based on the narrow class principle of equality, solidarity and freedom. It was easily declared from the stands, but in practice it was not carried out, because the militant spirit of radical intransigence and intolerance permanently triumphed in it (Scherer Y., 1995).

The Russian revolution, unlike all European ones, had a fundamental uniqueness, manifested in the fact that the dominant social groups of the population could think and act in a particular, specific radical-solidarist range. $\mathrm{N}$. Berdyaev narrates that "the Russian people in their bottoms are immersed in the chaotic, pagan yet earthen elements, and live on their peaks in apocalyptic aspirations, crave the absolute and do not reconcile with anything relative" (Berdyaev N., 1990). At the time, A.I. Herzen called it "the Russian autocracy the other way around." Subsequently, the Soviet power, established on a party basis, impregnated with the concept of class struggle impressed the radical consciousness of the masses, inclined to marginal forms of solidarization, which could not but be reflected in the totalitarian trajectory of the further path.

\section{CONCLUSIONS}

So, the detectable algorithm of the historical path of the Russian civilization allows us to include the phenomena under investigation in the range of phenomena included in its content, since they act as system guides of the zigzag trajectory of social change. Throughout the considered eras of the Russian civilization, its key actors in the person of individuals, ethnic groups, the masses, political elites, church and state allowed the laws of historical development to manifest themselves, including through such forms of social relations as radicalism and solidarity. Under their influence deepseated reactions of adaptation to internal and external challenges occurred. The tendency towards radical and solidary forms of interaction of various participants in the civilization process, especially during the tragic moments of historical changes in the frontier eras, was a special form of manifestation of social dynamics. Its total completeness, expressed, among other things, through the acceleration or deceleration of the processes of adaptation to historical reality, became a state of self-disclosure of specific subjects of social action, acting as vehicles of unknown metahistorical forces.

\section{ACKNOWLEDGEMENT}

The work is performed according to the Russian Government Program of Competitive Growth of Kazan Federal University.

\section{REFERENCES}

1. Berdyaev N. (1990) the fate of Russia. Experiments on the psychology of war and nationality. M., 141-142.

2. Blais M.-C. (2007) La solidarité: Histoire d'une idée. P.: Gallimard, 347 p.

3. Dal V. (1995) Explanatory Dictionary of the Living Great Russian Language. In 4 t. T. 4. M.: Thought, 611 p.

4. Eisenstadt S. (1978) Revolution and Transformation of Societies. A Compartive Study of Civilizational. N.Y, $139-145$.

5. Glinchikova A.G. (2014) Russia and Europe: Two Ways to the Present. M.: Cultural Revolution, 608 p. 
6. Grossman G. (1970) the Solidary Society: A Philosophical Issue in Communist Economic Re-forms // Carl Landauer. Ed. By Gregory Grossman. UN of California, Berkeley Prentice Hall, Inc. Englewood Cliffs, New Jersey, $187 \mathrm{p}$.

7. Hegel G.W.F. (1959) Sämtliche Werke. T. IV, 487 p.

8. Klyuchevsky V.O. (1990) Course of Russian history: op. in 9 t. M., Vol. 1, 85-87.

9. Likhachev D.S, (1990) On the National Character of Russians, // Philosophy Questions. No. 4, 3-6.

10. Malinkovich V. (2008) Vek is dislocated ... The link of times has collapsed. On the European system of values in a historical context. M.: IGPI, $350 \mathrm{p}$.

11. Martin N.G., Eaves L.J., Heath A. C.Et. al. (1986) Transmission of social attitudes, Proc. Nat. Acad. Sci. USA. V. 83, 364-4368. https://doi.org/10.1073/pnas.83.12.4364

12. Modern philosophy: Dictionary and reader Rostov-on-Don, Phoenix, (1995), 573 p.

13. Navarrete C. D., Fessler D. M., (2006) Disease avoidance an ethnocentrism: sensitivity and intergroup attitudes, Evolution and Human Behavior, V. https://doi.org/10.1016/j.evolhumbehav.2005.12.001

14. Political Science Dictionary. (1994) In 2 hours. Part 2 Ed. A. Ya. Migolanteva. M., 368 p.

15. Ridley M. (2014) The origin of altruism and virtues: from the struggle for survival - to cooperation. M.: Eksmo, 336 p.

16. Rittikh A. A. (1903) Peasants dependence on the community and the world. SPb Type. V.F. Kirschbaum, 126 $\mathrm{p}$.

17. Russia between Europe and Asia: Eurasian Temptation. (1993) M.: Science, 368 p.

18. Scherer Y. (1995) Religious and Philosophical Quest in Russia at the Beginning of the 20th Century, History of Russian Literature. Silver Age / ed. J. Niva, I. Serman, V. Strada, E. Etkind. M., 189 p.

19. Soloviev V.S. (1988) Justification of Good // Soloviev V.S. Soch. T. 1. M .: Thought, 47- 549.

20. Soloviev V.S. (1990) Three speeches in memory of Dostoevsky, About Dostoevsky: Dostoevsky's creativity in Russian thought of 1881-1931 comp. M. Borisov, A. B. Roginsky. M .: Book, 32-54.

21. Spiridonov V.I. (2008) Evolution of the idea of the state in the Western and Russian socio-philosophical thought / Rus. Acad. Sciences, Institute of Philosophy. Moscow: IPh RAS, 186 p.

22. Toynbee A. (1991) Comprehension of the history of Moscow: Progress, 736 p. 